\section{- tRABALHO dO MITO: DIÁlogos ENTRE FREUD E LÉVI-STRAUSS}

\author{
Mariza Martins Furquim Werneck
}

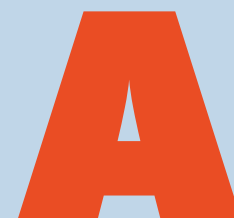

$s$ relações entre a psicanálise e a antropologia sempre foram marcadas por polêmicas, embates e desconfianças mútuas. Desenvolveram-se, como em toda relação analítica, entre o fascínio e a recusa.

Tudo começou quando Freud, na primeira década do século XX, interessou-se pela origem da humanidade e os fundamentos da cultura, para aí tentar decifrar o sentido das interdições presentes em todas as sociedades humanas. Totem e tabu (1) utiliza, entre suas fontes, os trabalhos dos antropólogos James Frazer, Robertson Smith e Edward Tylor, todos eles fortemente marcados pelas teorias evolucionistas.

A reação dos antropólogos anglo-saxões, que, nesse momento, já teciam duras críticas ao evolucionismo, não se fez esperar. A mais contundente delas foi a de Bronislaw Malinowski que, a partir de observações obtidas em seu trabalho de campo, nas ilhas Trobriand, situadas na Nova Guiné, negou, entre as ideias defendidas por Freud, a universalidade do complexo de Édipo e a origem única da humanidade. Para ele, e bem ao contrário disso, a organização matrilinear dos trobriand deixava vazio o lugar do pai, ao mesmo tempo em que afirmava a diversidade das culturas.

Esse debate não cessou aí, mas seria inútil relatá-lo por inteiro. $\mathrm{O}$ que interessa ressaltar, nos limites deste artigo, são os desdobramentos que ganha, a partir do final dos anos 1940, na obra do etnólogo francês, Claude Lévi-Strauss.

Em As estruturas elementares do parentesco (2), seu livro de estreia, Lévi-Strauss retoma essa discussão e interroga os fundamentos da proibição do incesto para repensá-lo em novas bases. Para ele, o tabu do incesto assinala a passagem da natureza para a cultura, argumento que possui um valor puramente formal, e não histórico.

Afirmando, ao mesmo tempo, tanto a universalidade da proibição do incesto quanto a diversidade das culturas, Lévi-Strauss resolve o impasse levantado pelas críticas de Malinowski às teorias freudianas. Com efeito, argumenta, se o tabu do incesto está presente em todas as sociedades humanas, não deixa de assumir, em cada uma delas, uma configuração particular, ditada por um regime de trocas matrimoniais regulado por estruturas que escapam à consciência individual.

Esse caráter inconsciente das estruturas sociais é o que interessa fundamentalmente à démarche levistraussiana: sua antropologia tenta colocar em cena as regiōes obscuras, as "leis escondidas" - expressão de Goethe, que sempre lhe foi cara - de onde se originam toda organização do pensamento humano. Esse interesse primordial é que vai, desde o início, aproximá-lo de Freud.

Como afirma em Tristes trópicos (3), assim que entrou em contato com a teoria freudiana, Lévi-Strauss percebeu que o etnólogo lidava, no plano coletivo, com o mesmo elemento que o psicanalista no plano individual, ou seja, um fenômeno aparentemente impenetrável, cujo deciframento não poderia jamais ser buscado em sua realidade mais evidente.

Em As estruturas elementares do parentesco Lévi-Strauss começa, a partir da linguística de Ferdinand de Saussure e de Roman Jackobson, a tematizar o campo do simbólico. A perspectiva que adota vai inovar os estudos sobre o tema, e constituir-se em uma das contribuições definitivas de seu pensamento.

Para ele, um elemento da cultura não pode jamais ser interpretado por si mesmo, mas unicamente enquanto está oposto a um, ou a vários outros elementos. Da mesma forma, não há um domínio de interpretação único, mas um conjunto de domínios, que Lévi-Strauss chama de "códigos”, onde as oposiçôes simbólicas se interpretam.

O mais importante de tudo - e também o mais intrigante - é que, para Lévi-Strauss, o simbólico é uma condição a priori da sociedade, e não uma decorrência. Considerado um fato primeiro, o simbolismo permite compreender a instituição mesma da sociedade, e todos os elementos de uma cultura como expressões desse simbolismo. A cultura, então, passa a ser definida como um conjunto de sistemas simbólicos, dentre os quais os mais importantes são a linguagem, as regras matrimoniais, as relaçôes econômicas, a arte, a ciência, a religião.

As concepções de Lévi-Strauss sobre o simbolismo vão ecoar, de forma profunda, na obra de Jacques Lacan e encontrar aí desenvolvimentos fundamentais para a renovação do campo do simbólico na teoria psicanalítica.

$\mathrm{O}$ arcabouço teórico da psicanálise juntamente com a linguística forneceram a Lévi-Strauss o método e a operacionalidade necessários para conferir à antropologia o estatuto de ciência. Sua interlocução com essas duas formas de conhecimento produziu, no início da segunda metade do século XX, um dos diálogos mais fecundos, não apenas para a antropologia, como para as ciências humanas como um todo.

Como ele mesmo afirma, seu encontro com Roman Jakobson, nos tempos de exílio em Nova Iorque, durante a Segunda Guerra, ultrapassou em muito a sua primeira expectativa, que era a de aprender a fazer corretamente a notação de certos termos indígenas. A revelação da linguística estrutural, diz ele, trouxe-lhe a possibilidade de poder formular em um corpo de ideias coerentes o que antes eram apenas intuiçôes e devaneios. A contribuição capital que a linguística, desde Saussure, trouxe às ciências humanas foi a de sublinhar o papel que desempenha na produção da linguagem, e em todos os sistemas simbólicos, a atividade inconsciente do espírito.

Quanto a Freud, a leitura de sua obra, realizada precocemente, deixou marcas profundas na formação de seu pensamento. A ideia de transformar o exercício da etnologia em uma espécie de experiência intima, se tem um ponto de partida em Jean-Jacques Rousseau encontra, nos diálogos com Freud, um dos momentos mais altos de elaboração.

A partir desses diálogos, Lévi-Strauss, vai, entre outras coisas, produzir um artigo famoso, "O feiticeiro e sua magia" (4) em que vai identificar os procedimentos de cura utilizados pelo xamã com os do psicanlista. 
Muitos anos mais tarde, em $A$ oleira ciumenta (5), em um momento de franca crítica à psicanálise, vai conceder a um mito jivaro, semelhante ao da horda primitiva descrito por Freud em Totem e tabu a precedência da descoberta de categorias centrais reivindicadas pela psicanálise.

Entre esses dois momentos, Lévi-Strauss realizou seu grande projeto, Mitológicas (6) em que analisou milhares de mitos e suas variantes, trabalho do qual pode-se dizer, sem sombra de dúvida, que não é em nada menos ambicioso do que o realizado por Freud em $A$ interpretação dos sonhos (7). Entre as diversas chaves que the permitiram o acesso às estruturas inconscientes do mito uma das mais significativas foi, certamente, o método psicanalítico.

Assim como as categorias construídas na linguística por Ferdinand de Saussurre e Roman Jakobson refletiram-se no modelo de análise estrutural do parentesco, a tal ponto que alguns comentadores consideraram abusiva sua apropriação, o modelo freudiano de análise do sonho se explicita e se espelha na interpretação levistraussiana do mito de maneira inequívoca.

Se Freud foi buscar no delírio psicótico, decifrado pela psiquiatria de seu tempo como a realização de um desejo recalcado, a mesma chave para pensar o sonho, Lévi-Strauss projetou no mito a realização de um desejo coletivo inconsciente: para ele, o mito existe para resolver uma contradição que a sociedade não sabe resolver. Por isso, assim como o sonho, ele não pode jamais ser apreendido em sua literalidade. Mas, ao se falar em desejo inconsciente coletivo é preciso que se guardem, aqui, as devidas distâncias do pensamento junguiano, cuja proximidade jamais foi reconhecida por Lévi-Strauss. É de Freud que se trata.

O projeto das Mitológicas foi antecedido de uma longa preparação. Segundo Lévi-Strauss, o trabalho de campo, vivido no Brasil nos anos 1930 teve, para ele, o mesmo sentido da análise didática para a iniciação da prática psicanalista: “(...) o campo representou para mim o que a psicanálise didática pode significar para um analista: a obrigação de viver, de criar, de reviver as experiências por si mesmas, para poder utilizar mais adiante as investigaçōes de "campo" desenvolvidas por outros. Este representou para mim uma espécie de iniciação preliminar" (8).

A incursão levistraussiana pela terra oca e redonda do mito foi concebida como uma viagem por uma imensa região agreste. Curiosamente, Freud utiliza-se quase que da mesma imagem para figurar a sua incursão pelo universo onírico. Em uma carta a Wilhelm Fliess, datada de agosto de 1899, depois de ter escrito o primeiro capítulo de $A$ interpretação dos sonhos afirma: "A coisa está planejada segundo o modelo de um passeio imaginário. No começo, a floresta escura dos autores (que não enxergam as árvores), irremediavelmente perdidos nas trilhas erradas. Depois, uma trilha oculta pela qual conduzo o leitor - meu sonho paradigmático, com suas particularidades, pormenores, indiscrições e piadas de mau gosto - e então, de repente, o planalto com seu panorama e a pergunta: em que direção você quer ir agora?” (9).

A metáfora da viagem imaginária definiu, para Lévi-Strauss, até mesmo o título das Mitológicas, por analogia com as Bucólicas e as Geórgicas de Virgílio. A imagem volta insistentemente em toda a tetralogia levistraussiana, assim como o topos da floresta escura. Mas, entre Freud e Lévi-Strauss, uma sutil diferença: se Freud conduz o leitor perdido através de seu sonho paradigmático, o mito que se pensa em Lévi-Strauss traz-lhe a sensação de ele próprio estar perdido, sem complacência: "As Mitológicas ilustram o desenrolar, quase o dia a dia, de um trabalho de descoberta. Eu labutava em uma floresta virgem que, para mim, era um mundo desconhecido. Abria laboriosamente uma trilha através dos cerrados e dos maciços quase impenetráveis" (10).

Se o uso da mesma metáfora é um argumento ainda precário para atestar qualquer semelhança entre métodos, a utilização de um mito paradigmático, talvez sirva como uma demonstração mais contundente. Com efeito, em O cru e o cozido, primeiro volume das Mitológicas, é, inicialmente, a partir de um único mito - o mito bororo do desaninhador de pássaros - que Lévi-Strauss vai construir o seu modelo de análise, em consonância direta com o sonho "da injeção de Irma”, paradigma da análise freudiana.

Devedor confesso do pensamento freudiano, Lévi-Strauss, no entanto, nunca esclareceu em que medida as categorias criadas por Freud para pensar o sonho projetaram-se e tornaram-se operadores poderosos em seu trabalho sobre os mitos. Embora não tenha se escusado de revelar suas fontes, ou seus operadores, como prefere dizer, Lévi-Strauss sempre cultivou o gosto de deixar em seus escritos pequenos enigmas.

Não agiu de forma diferente com a obra de Freud. O confessado fascínio, ou mesmo algumas recusas mais veementes do pensamento de Freud legíveis em sua obra constituem apenas o registro mais visível, e não dão conta da exata dimensão de suas dívidas metodológicas e epistemológicas para com o fundador da psicanálise.

O que se pode assegurar é que, assim como Freud visava, em suas construções teóricas, produzir modelos conceituais, afastados da experiência, a partir dos quais a própria experiência pudesse ser transformada, Lévi-Strauss produziu modelos estruturais a partir dos quais os mitos podem ser pensados e, mais do que isso, depreendidos.

O ponto de partida comum aos dois pensadores é a ideia de que sonhos e mitos nascem de uma atividade mental inconsciente, à qual só se tem acesso por meio de um método específico de análise, seja o método psicanalítico de interpretação dos sonhos, seja a análise estrutural dos mitos. A afirmação de Freud de que "os sonhos são a via régia que leva ao conhecimento das atividades inconscientes da mente" reproduz-se quase que literalmente em Lévi-Strauss, no que se refere aos mitos.

Como se vê, as possibilidades de aproximação entre uma e outra obra são inúmeras, e seria leviano pretender enumerá-las todas nos limites deste artigo. Apenas a frequentação sistemática e intensa de seus textos é que poderá definir em que medida a trilha oculta, proposta por Freud, em busca do deciframento dos sonhos, cruzase com a trilha laboriosamente aberta por Lévi-Strauss, através dos cerrados e dos maciços quase impenetráveis, em busca dos mitos.

As mais diversas afinidades aproximam os dois pensadores, até mesmo do ponto de vista biográfico, a começar pela partilha da condição judaica. Podemos citar Goethe, entre outros autores prediletos, as ciências naturais, o gosto por retratos (pictóricos, em 
Lévi-Strauss, fotográficos, em Freud), a atração por ruínas, pelas linguagens enigmáticas como o rébus e os hieróglifos, os caleidoscópios. E o desgosto pela filosofia. De uma forma ou de outra, todos esses elementos entraram na composição de suas obras.

SUJEITO E IMAGEM NO TERRENO DAS METÁFORAS Se continuarmos no terreno das metáforas, considerando-as não um simples ornamento de estilo, mas vias de acesso ao pensamento dos dois autores, os exemplos são inúmeros, e riquíssimos.

Para isso, seria interessante invocar aqui o trabalho de Hervé Huot em Do sujeito à imagem: uma história do olho em Freud (11) que, ao tratar as metáforas do olhar "que atravessam a vida, a prática e a obra de Freud", como altamente significativas para uma compreensão mais ampla da imagética psicanalítica, examina, entre outras coisas, as relaçôes de Freud com a arte, com os aparelhos ópticos (microscópios, telescópios, aparelhos fotográficos e caleidoscópios) com o "teatro" de Charcot, e a descrição do inconsciente como "cena psíquica”.

As invenções do cinematógrafo, pelos irmãos Lumière, e da psicanálise, por Freud, coincidem no tempo: pertencem ao último decênio do século XIX. Longe de serem acontecimentos estranhos entre si, Huot acredita que eles produzem, cada um à sua maneira, uma nova relação do sujeito com a imagem. Vale lembrar que Walter Benjamin atribuía à invenção do cinema e da fotografia a ampliação do que denominava "inconsciente óptico", da mesma forma que a psicanálise ampliou o inconsciente pulsional.

Essa análise é importante na medida em que a visão do mito em Lévi-Strauss é construída a partir das mesmas metáforas: o caleidoscópio, a câmara de espelhos, e um olhar sobre o mundo adestrado pela frequentação da pintura e das artes em geral. A descrição do "lugar psíquico", lugar privilegiado da cena psicanalítica, também conhecido como inconsciente, encontra seu paralelo em LéviStrauss por meio da metáfora da câmara de espelhos, que ele semeia em toda sua obra.

ESPELHOS DE FREUD Numa discussão preliminar pode-se dizer que Lévi-Strauss, à maneira de Freud, abriga seus fragmentos de mitos em um lugar tão secreto como a máquina óptica postulada por Freud: imagina um quarto de espelhos onde, por meio de uma fresta, ou de uma pequena abertura pontual, pela qual penetram raios de luz, pode surpreender o mito em suas quase infinitas variações. Essa câmara de espelhos, imagem barroca por excelência, onde tudo é reflexo, é descrita de diferentes maneiras ao longo de sua obra. Assim como a matéria mítica, e assim como os sonhos, esse recinto secreto vai e volta, se deforma, ou se inverte.

Às vezes assume a forma de um instrumento óptico, como os utilizados por Leonardo da Vinci ou Albrecht Dürer, para desvendar as leis da perspectiva. Em outros momentos se metamorfoseia em uma câmara obscura. Uma de suas variantes é o espelho deformante, com o qual, conferindo visibilidade ao próprio exercício do pensamento, fecha A oleira ciumenta. O caleidoscópio - igualmente uma metáfora freudiana - pode ser pensado como a versão miniaturizada dessa câmara de espelhos, seu modelo reduzido, por meio do qual podem ser observados os estilhaços de mitos, seus dejetos e ruínas, transfigurados em magníficas rosáceas luminosas.

Dessa forma, os mitos projetam modelos de inteligibilidade sobre o modus operandi do espírito humano. Penetrar na lógica desse caleidoscópio, no entanto, não é tarefa fácil. Exige, como afirma Lévi-Strauss, uma espécie de ascetismo, pois o seu deciframento é longo e penoso. Quem nele se aventura, certamente, como nos ritos iniciáticos, ou no processo analítico, sairá transformado.

Mariza Martins Furquim Werneck é professora de antropologia na Pontificia Universidade Católica de São Paulo (PUC-SP) e sua tese de doutorado trata dos operadores estéticos na obra de Claude Lévi-Strauss.

\section{REFERÊNCIAS BIBLIOGRÁFICAS}

1. Freud, S. "Totem e tabu". In: S. Freud. Edição standard brasileira das obras psicológicas completas de Sigmund Freud. (Vol. 13). Rio de Janeiro: Imago. Trabalho original publicado em 1912. 1974.

2. Lévi-Strauss, C. As estruturas elementares do parentesco. Tradução de Mariano Ferreira. Petrópolis: Vozes; São Paulo: Edusp. Trabalho original publicado em 1949.1975.

3. Lévi-Strauss, C. Tristes trópicos. Tradução de Rosa Freire d' Aguiar. São Paulo: Companhia das Letras. Trabalho original publicado em 1955. 1996.

4. Lévi-Strauss, C. "O feiticeiro e sua magia". In: Antropologia estrutural. Tradução de Chaim Katz e Eginardo Pires. Rio de Janeiro: Tempo Brasileiro. Trabalho original publicado em 1958.1970

5. Lévi-Strauss, C. A oleira ciumenta. Tradução de Beatriz PerroneMoisés. São Paulo: Brasiliense. Trabalho original publicado em 1985. 1986.

6. Lévi-Strauss, C. "O cru e o cozido". In: Mitológicas. Vol. 1. Tradução de Beatriz Perrone-Moisés. São Paulo: Cosacnaify. Trabalho original publicado em 1964.1991.

7. Freud, S. "Interpretação dos sonhos". In: S. Freud, Edição standard brasileira das obras psicológicas completas de Sigmund Freud. (Vol. 4/5). Rio de Janeiro: Editora Imago. Trabalho original publicado em 1990-1901. 1974.

8. Lévi-Strauss, C. "Entrevista a Raymond Bellour". In: Elogio de la antropología. Buenos Aires: Ediciones Caldén. 1975.

9. Freud, S. Correspondência completa de S. Freud para W. Fliess. Rio de Janeiro: Imago, p.52.1940.

10. Lévi-Strauss, C. De près et de loin. Paris: Éditions Odile Jacob. 1988.

11. Huot, H. Do sujeito à imagem: uma história do olho em Freud. São Paulo: Escuta. 1991. 